\section{Safety issue with TT380 Slimline intrauterine contraceptive device: response to Karen Trewinnard and Colin Parker}

Karen Trewinnard reported failure of a TT380 Slimline device to release into the uterine cavity, ${ }^{1}$ and Colin Parker has replied that changes in the manufacturing are being addressed to reduce the incidence of the device kinking. ${ }^{2}$ My own experience of inserters kinking and not releasing the device during insertion is that this most often happens when the device has not entered the endometrial cavity correctly. Usually the fitter will have noted resistance during the insertion, and on withdrawing the inserter tube things do not feel right. I am fortunate to have ultrasound for assessing any such difficulty. Framed devices cannot deploy correctly when released in a false passage. In some cases the device will remain in the inserter tube, which may kink during attempted release. In other cases the device may be forcibly released into the false passage. The incorrect position can readily be recognised with ultrasound (figure 1). Marked retroflexion will increase the risk of this occurring.

In my experience this is not a safety issue with the TT380 Slimline. It may occur with any intrauterine device or system where the fitter does not recognise and manage to negotiate an acute angulation of the cervico-isthmic junction correctly during insertion. The change in the angle of insertion required at the cervico-isthmic junction may not be possible with standard inserter tubes for any type of intrauterine contraceptive (IUC) as they are all flexible. In many cases of acute flexion I have found it necessary to reduce the angle using a metal dilator and then insert the IUC as the dilator is withdrawn. The failure of the device releasing from the insertion tube may actually prevent placement in a false passage.

It may be difficult for those fitting without ultrasound to appreciate that bimanual assessment may not enable the fitter to know the exact position and degree of angle change needed during insertion to successfully pass from the endocervical into the endometrial canal, particularly with an acute retroflexion angle (figure 2). Where difficulty has been encountered with insertion, particularly where release of the device does not feel quite right, there should be a

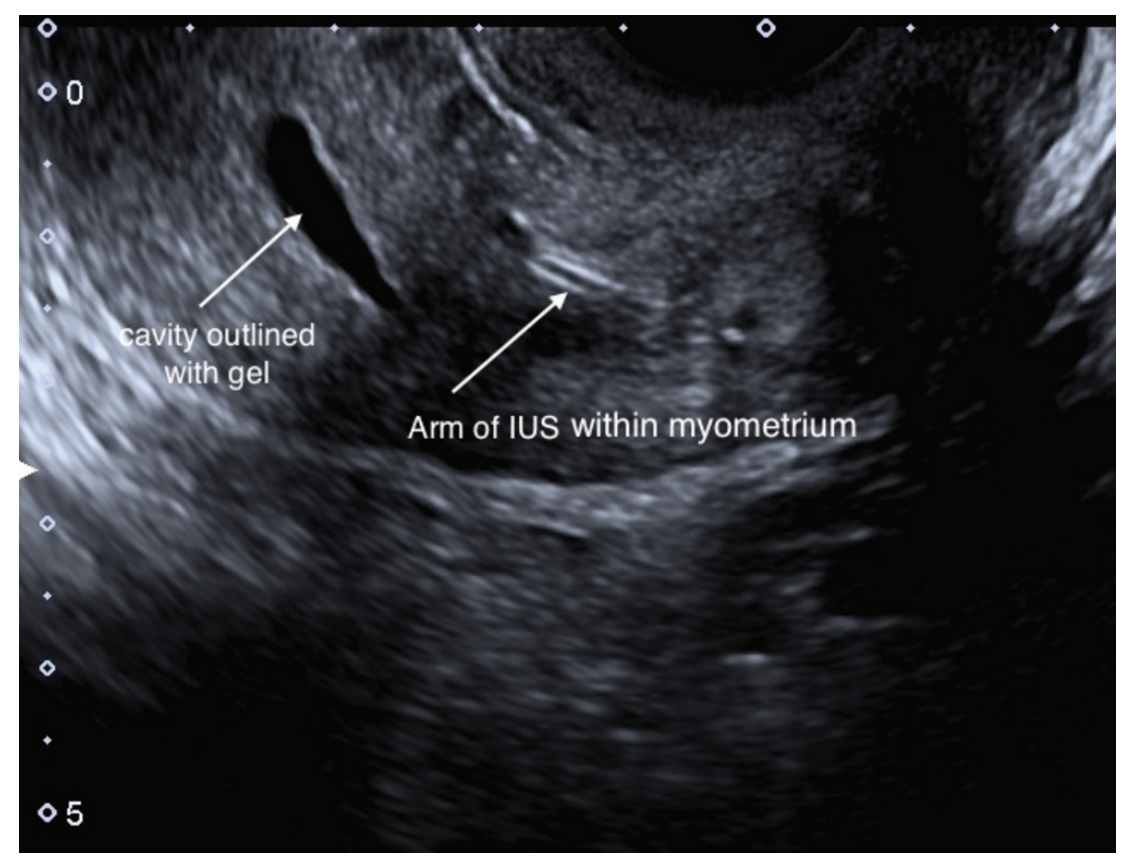

Figure 1 Patient referred for ultrasound assessment following a difficult intrauterine system (IUS) fitting that 'did not feel right'. This long axis view of the uterus shows the endometrial cavity has been filled with negative contrast (Instillagel). Parts of the frame of the IUS can be seen within a false passage in the myometrium. 


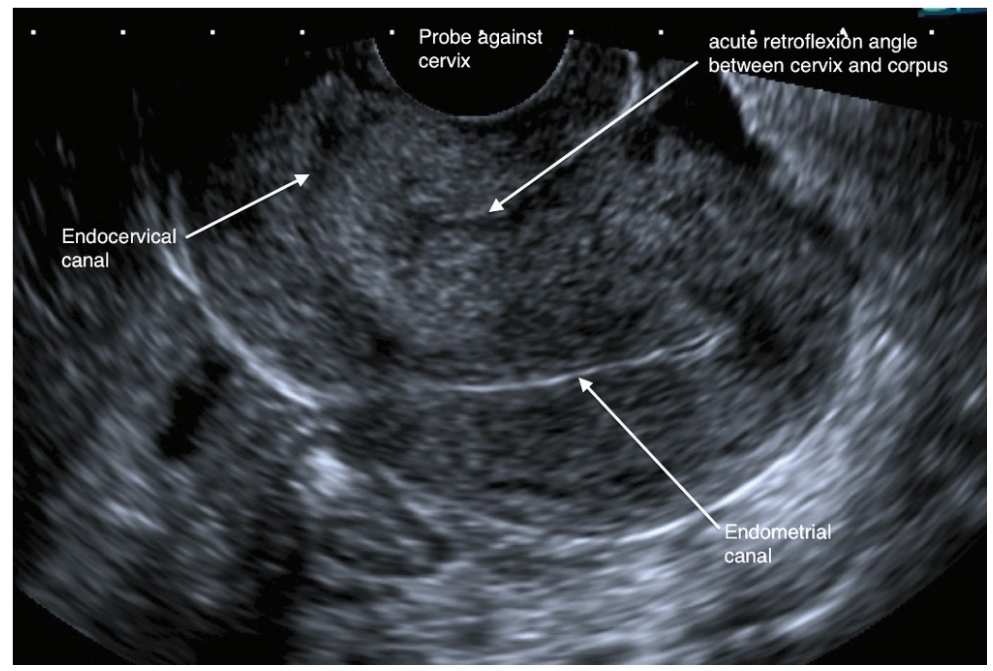

Figure 2 Patient referred following a failed intrauterine device fitting. This long axis view shows the cervix directly anterior to the corpus due to an acute angle of retroflexion. To successfully enter the endometrial cavity any device will have to be angled posteriorly more the $90^{\circ}$ at the level of the cervico-isthmic junction during insertion.

low threshold for requesting ultrasound. Misplacement is otherwise unlikely to be recognised until later attempts at removal fail because the device has become embedded in the myometrium.

\section{Mary Pillai ${ }^{1,2}$}

${ }^{1}$ Sexual Health Service, Gloucestershire Care Services NHS Trust, Gloucester, UK

${ }^{2}$ Department of Obstetrics, Gloucestershire Hospitals NHS Foundation Trust, Gloucester, UK

Correspondence to Dr Mary Pillai, Sexual Health Service, Gloucestershire Care Services NHS Trust, Gloucester, Gloucestershire, UK; mary.pillai@nhs.net

Contributors I am the sole author of the manuscript which is entirely my own and is original. The figures are my own and none of the content has been published or submitted elsewhere.

\section{Competing interests None declared.}

Provenance and peer review Not commissioned; internally peer reviewed.

(C) Article author(s) (or their employer(s) unless otherwise stated in the text of the article) 2018. All rights reserved. No commercial use is permitted unless otherwise expressly granted.

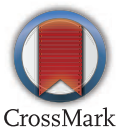

Published Online First 8 November 2017

BMJ Sex Reprod Health 2018;44:68-69. doi:10.1136/jpprhc-2017-101894

\section{REFERENCES}

1 Trewinnard K. Safety issue with TT380 Slimline intrauterine contraceptive device. J Fam Plann Reprod Health Care 2017;43:241-242.

2 Parker CG. Response to 'Safety issue with TT380 Slimline intrauterine contraceptive device'. J Fam Plann Reprod Health Care 2017;43:242. 